\title{
LA POÉTICA, LA RETÓRICA Y EL MUNDO DE LA VIDA
}

\section{LUZ GLORIA CÁRDENAS MEJÍA ${ }^{1}$}

\section{"Digamos que el mundo es una figura, hay que leerla. Por leerla entendamos generarla."}

Rayuela. Julio Cortázar

Resumen: Este artículo tiene por objeto señalar las relaciones que Paul Ricoeur establece entre hemenéutica, poética y retórica, siguiendo los planteamientos aristotélicos; a su vez, se dejan esbozadas algunas implicaciones para las ciencias sociales. Este trabajo está dividido en seis parágrafos, así: 1. Hermenéutica, poética y retórica; 2. Discurso poético y retórico; 3. El poeta y el historiador, 4. El espacio público: la retórica; 5. Retórica, teoría de la argumentación y teoría de la elocución; 6. La retórica en situación.

Palabras clave: retórica, poética, mundo de la vida, ciencias sociales, hermenéutica, acción, texto, lenguaje, espacio público, discurso, argumentación.

Abstract: This article has for goal to point out, following Aristotelian positions, the relationships that Paul Ricoeur establishes among hermeneutics, poetic and rhetoric. In turn, some implications for the social sciences are sketched. This work is divided in six parts entitled as follows: 1. Hermeneutics, poetic and rhetoric; 2. Poetic and rhetorical speech; 3. The poet and the historian, 4. Public space: the rhetoric; 5. Rhetoric, argument theory and elocution theory; 6 . The rhetoric in situation.

Key words: rhetoric, poetic, world of the life, social sciences, hermeneutics, action, text, language, public space, speech, argument.

\section{Hermenéutica, poética y retórica}

Ricoeur en su artículo El modelo del texto: la acción significativa considerada como un texto (1971), establece que si las ciencias sociales son hermenéuticas, tal afirmación descansaría en el hecho de poder establecer que su objeto revele las características de un texto y que en su metodología desarrolle los mismos procedimientos de la interpretación de textos. Para Max Weber, según Ricoeur, el objeto de las ciencias sociales se define como "conducta orientada significativamente", y se pregunta: "¿en qué medida se puede reemplazar el predicado 'orientada significativamente', por lo que me

gustaría llamar caracteres de legibilidad derivados de la teoría precedente del texto?". ${ }^{2}$ Para mostrar lo anterior, establece la analogía entre texto y acción, a

\footnotetext{
${ }^{1}$ Prof esora Instituto de Filosofía Universidad de Antioquia

${ }^{2}$ RicoeurPaul, "El modelo del texto: la acción significativa considerada como texto". En: Del texto a la acción. Ensayos de hermenéutica II. México, Fondo de Cultura Económica, 2002, p. 175.
} 
partir de los rasgos que los constituyen desde una teoría del discurso, construyendo con ello la posibilidad de una hemenéutica de la acción social. Nuestra intención no es presentar esta posibilidad, sino mostrar cómo Ricoeur reconfigura este proyecto en dos de sus obras, La Metáfora Viva (1975) y Tiempo y Narración I, II, III (1983, 1984,1985).

Los profesores Guillemo Hoyos Vásquez y Germán Vargas Guillén en La teoría de la acción comunicativa como nuevo paradigma de investigación en Ciencias Sociales: las ciencias de la discusión, plantean que las ciencias sociales tienen una tarea que cumplir con respecto al mundo de la vida: la "construcción de formas de interacción social, racionalizadas desde las 'ciencias de la discusión', antes que explicar, predecir o controlar el comportamiento humano, tiene que descubrir y hacer manifiesto el conjunto de razones y motivos que dan origen a la construcción de la opinión pública, de la sociedad civil, de las formas de entendimiento y de comprensión". 3 Queremos enlazar esta tarea con la hermenéutica de los textos propuesta por Paul Ricoeur, la cual impone una importante restricción a una hemenéutica que, en sus comienzos, se dirigía al amplio campo de los signos y de los símbolos. "La mediación a través de los textos parece reducir la esfera de interpretación a la escritura y a la literatura en detrimento de las culturas orales. Esto es cierto. Pero, lo que la definición pierde en extensión, lo gana en intensidad. En efecto, la escritura otorga recursos originales al discurso,(...) en primer lugar identificándolo con la oración (alguien dice algo sobre algo a alguien), luego caracterizándola mediante la composición de series de oraciones en forma de relato, poema o ensayo". "Con esta hermenéutica una nueva ontología se despliega, en la que los textos "pretenden llevar al lenguaje una experiencia, un modo de vivir y de estar-en-el mundo que lo precede y pide ser dicho". Acceder al mundo de la vida, por el largo rodeo de los textos, permite ampliar nuestra comprensión sobre dicho mundo, y así el diálogo de la filosofía con las Ciencias Sociales, en palabras de Ricoeur, se mantiene.

\section{Discurso poético y retórico}

Partamos, entonces, de la idea propuesta por Ricoeur, los textos dicen a su manera la acción. Por ello nos ocuparemos de precis ar la forma en que lo hacen el discurso poético y el retórico. Es necesario, decir ante todo, que ellos no nos hablan de la acción tomada individualmente; quizás habría un límite para hacerlo; pues cada vez que intentamos expresar la comprensión de una determinada acción, las enlazamos con otras. En los textos poéticos y retóricos expresamos la acción humana, la cual es configurada desde la orientación hacia otros, "sólo sobre la base de esta orientación hacia otros puede hablarse de acción social.

\footnotetext{
${ }^{3}$ Hoyos Vásquez Guillermo. Vargas Guillén Germán. La teoria de la acción comunicativa como nuevo paradigama de investigación en ciencias sociales: las ciencias de la discusión. Bogotá, ICFES, ASCUM, 1996, p. 18.

${ }^{4}$ RicoeurPaul.“Acerca dela interpretación”. En:Del texto a la acción. Ensayos de hermenéutica II., p. 33.

${ }^{5}$ Idem p. 35. 
Pero esto todavía no es todo. Es necesario agregar a la noción de acción social la de relación social, entendiendo por ello un curso de acción en la cual cada individuo no sólo tiene en cuenta la reacción que tienen los otros, sino que motiva su acción con símbolos y valores que ya no expresan caracteres de deseabilidad privados hechos públicos, sino reglas que son en sí públicas". 6

En la teoría del discurso propuesta por Ricoeur, este decir es un acontecimiento: "alguien dice algo a alguien sobre algo". 7 Con el recorrido que realiza este autor por la poética y la retórica, se podría añadir que la acción social accede al discurso y propicia cambios en el mundo. Con el fin de mostrar lo precedente se hará un recorrido por la teoría de la poética elaborada por Ricoeur. En la primera parte, se expone el recorrido que se construye, del llamado por él arco hermenéutico, el cual se despliega des de la prefiguración del mundo de la vida, a la configuración poética y, a partir de ésta, a la refiguración del mundo del lector, con el fin de presentar el lugar de la poética en el mundo de la vida. En la segunda parte se hace una presentación de la retórica, desde los planteamientos de Aristóteles y Ricoeur, con el fin de ubicar el lugar de la retórica. Se efectuará una distinción entre dos tipos de retórica, una de carácter general y otra en situación, con el fin de exhibir cómo desde esta última, es posible pensar el piso desde el cual se levanta la retórica y se dispone o mueve a la acción. Las diversas precisiones que se indicarán buscan primero, con relación a la poética, mostrar con Ricoeur la forma en que se amplía nuestro imaginario; y res pecto de la retórica, cómo desde nuestro imaginario tomamos decisiones y valoramos.

\section{El poeta y el historiador}

Paul Ricoeur en Tiempo y Narración es tablece: "el tiempo se hace tiempo humano en cuanto se articula de modo narrativo; a su vez la narración es significativa en la medida que describe los rasgos de la experiencia temporal". ${ }^{8}$ Con el fin de extender el valor de tal afirmación, Ricoeur recupera para la reflexión la Poética de Aristóteles y las Confesiones de San Agustín; en estos textos encontrará la posibilidad de construir una teoría del relato que pueda comprender desde la tragedia griega a todos los géneros literarios y a la historia, y una fenomenología del tiempo que le permita, desde la aporía del tiempo, enunciada por San Agustín y retomada por Husserl y Heidegger, afimar que la paradoja del tiempo exige su expresión en la narración.

La idea de Aristóteles, que recoge Ricoeur, al definir la tragedia como mímesis, señala que ésta debe ser comprendida como imitación creadora y no según corrientemente se la ha entendido, como simple copia. Esta idea permite comprender por qué Ricoeur habla, más bien, de actividad mimética y de construcción de la trama, y por qué ello exige indagar las operaciones que las

\footnotetext{
${ }^{6}$ Idem p.224.

${ }^{7}$ RicoeurPaul. "Rhétorique, poétque, herméneutique" (1990) En: Lectures 2. La contrée des philosophes. Paris, Éditions du Seuil, 1992, p. 479.

${ }^{8}$ RicoeurPaul, Tiempo y narración. Configuración del tiempo en el relato histórico. México, Siglo Veintiuno Editores, S. 1995, p. 36.
} 
hacen posible. Con el fin de dar respuesta a lo anterior, Ricoeur, establece el modelo de las tres mímesis: "mi tesis es que el sentido mismo de la operación de configuración constitutiva de la construcción de la trama resulta de su posición intermedia entre las dos operaciones que yo Ilamo mímesis I y mímesis III y que constituyen 'el antes' y 'el después' de mimes is II. Con esto me propongo mostrar que mimesis II consigue su inteligibilidad de su facultad de mediación, que consiste en conducir del antes al después del texto, transfigurar el antes en después por su poder de configuración".

Con el fin de comprender lo que significa mímes is I, Ricoeur expone lo que serían sus tres componentes: la red conceptual de la acción, los recursos simbólicos y los caracteres temporales; los cuales adquirimos familiarizándonos con ellos. La red conceptual supone una competencia que se desarrolla cuando somos capaces de identificar los distintos componentes de la red: agente, fines, motivos, circunstancias y la interacción con otros. Los recursos simbólicos provienen de los procesos culturales que articula la experiencia, los cuales pueden ser descifrados por otros, pues adquieren la visibilidad de lo público; desde estos se evalúan y se les adjudican valores a los distintos tipos de acciones. Con los caracteres temporales tenemos la experiencia de construir proyectos en el futuro y de movilizar en el presente la experiencia heredada del pasado. Partiendo de estos tres componentes no es posible comprender la forma como accedemos a su legibilidad. Son los materiales con los cuales el autor y el historiador construyen sus relatos de ficción y de historia, los que se identifican, según Ricoeur, por su estructura narrativa y se diferencian uno, por sus pretensiones de verosimilitud, el otro, de verdad; con ello se quiere explicar cómo la his toria toma prestado de la ficción la estructura narrativa y cómo la ficción toma de la historia sus pretensiones de verdad para hacerse verosímil.

Establecidas las bases de legibilidad del obrar humano, el trabajo es ahora para la configuración. Paul Ricoeur expresa: "la primera manera según la cual el hombre intenta comprender y dominar lo diverso del campo práctico es la de procurarse una representación ficticia de él. Ya sea que se trate de la tragedia antigua, del drama moderno, de la novela, de la fábula o de la leyenda, la estructura narrativa proporciona a la ficción las técnicas de abreviación, de articulación y de condensación mediante las cuales se logra el efecto icónico que describe también en la pintura y en las otras artes plásticas". ${ }^{10}$ Con la configuración, nos encontramos ya en mímesis II. Es aquí, donde Ricoeur propiamente vuelve sobre la Poética de Aristóteles para hacer ver cómo en ella confluyen dos operaciones aparentemente diversas; de quien construye la obra poética: la actividad mimética y la disposición de los hechos. "La imitación o la representación es una actividad mimética en cuanto produce algo: precisamente la disposición de los hechos mediante la construcción de la trama". ${ }^{11}$ Por medio de la elaboración de la trama se teje la conexión entre los diversos acontecimientos, sólo posible al imitar y, por

\footnotetext{
${ }^{9}$ Idem, p.114.

${ }^{10}$ RicoeurPaul."La imaginación en el disaurso y en la acción”. En: Hermenéutica y acción, Ensayos de hermenéutica II, p. 203.

${ }^{11}$ RicoeurPaul. Tiempo y narración Configuración del tiempo en el relato histórico, p. 85. 
tal efecto, crear una única acción. El orden de la composición, principio, medio, fin, permite la estructuración de este uno, que aparece como un todo: "las ideas de comienzo, medio, fin no se toman de la experiencia: no son rasgos de la acción efectiva, sino efectos de la ordenación del poema", ${ }^{12}$ el orden construido así se hace verosímil "uno después de otro es la sucesión episódica y por lo tanto lo inverosímil; uno a causa de otro es el encadenamiento causal y, de allí lo verosímil. Ya no cabe duda: lo universal que comporta la trama proviene de su ordenación; esta constituye su plenitud y totalidad (...) Componer la trama es ya hacer surgir lo inteligible de lo accidental, lo universal de lo singular, lo necesario o lo verosímil de lo episódico"; pero a su vez, con esta composición se instaura la desconexión que permite la literalidad de la obra literaria, pues no se puede decir que la obra es un espejo en donde simplemente se reflejan las acciones, una especie de distancia se teje allí y otro mundo se despliega por obra del poeta. "El creador de palabras no produce cosas sino sólo cuasi-cosas, inventa el como si". ${ }^{13}$ El como si, que producido imaginativamente lleva un sentido, se dirige hacia alguna parte, "por estar en el mundo y por soportar situaciones, intentamos orientamos sobre el modo de la comprensión y tenemos algo que decir, una experiencia que llevar al lenguaje, una experiencia que com partir". ${ }^{14}$

Si con este trabajo de configuración se da una especie de comprensión y de dominio sobre el campo práctico, nos preguntamos ¿qué tipo de comprensión es ésta y de qué tipo de dominio se trata? Ricoeur dice: las obras poéticas permiten suspender la primera referencia al campo práctico; al hacerlo, una segunda referencia aparece gracias al proceso de configuración de la obra poética, ¿de qué nos habla el poeta? "Abolición de la referencia ostensiva, aquélla que muestra lo que está ahí, a la mano, como sucede en la conversación, en la que se refiere por medio de los demostrativos (Strawson) a las cosas situadas, en el esquema espacio temporal, donde los interlocutores están, ellos mismos, incluidos. Es esta referencia ostensiva la que la poesía destruye. Es otro sentido de realidad la que la poesía libera, solidaria de lo que la ontología de Heidegger llama "ser en el mundo" y que exige el replanteamiento total de la relación sujeto-objeto, de los conceptos de existencia y realidad". ${ }^{15}$ Un mundo se abre, y cabe la posibilidad de habitarlo, tal como tantas veces nos lo recuerda Ricoeur. Es este el dominio, no el del poder de manipulación que ejercemos sobre las cosas y el cual continuamente pretendemos extender al mundo de los seres humanos, invasión que tantos otros filós ofos denuncian (Huss erl, Heidegger, Gadamer, Habemas).

Contra la afirmación del estructuralismo de una obra literaria cerrada sobre sí misma, que no habla de lo real, se pronuncia Ricoeur "el prejuicio de que sólo es real el dato que puede observarse empíricamente y describirse científicamente", hace que se encierre "la literatura en un mundo en sí y se rompe la parte subversiva que lanza contra el orden moral y social. Se olvida que la ficción es

\footnotetext{
${ }^{12}$ Idem p. 93.

${ }_{14}^{13}$ Idem p. 103.

${ }^{14}$ Idem p. 149.

${ }^{15}$ Ricoeur Paul, Hermenéutique. Louvain-la- Nueve. Cours professé à L'institut Supérieur de Philosophie 1971-1972, Editions du SIC, p. 180.
} 
precisamente la que hace del lenguaje ese supremo peligro del que Walter Benjamín, tras Hördelin, habla con temor y admiración”. ${ }^{16}$ La obra literaria si habla del mundo, pero de otra manera, nos invita Ricoeur a seguir el trayecto, ya no como círculo herméneutico de la comprensión, tal como lo expuso Heidegger en Ser y tiempo ${ }^{17}$ sino como arco hemenéutico que va de mimesis I a mimesis II, hasta mímesis III, corresponde a la hemenéutica su explicación, "incumbe a la hermenéutica reconstruir el conjunto de operaciones por las que una obra se levanta sobre el fondo opaco del vivir, del obrar y del sufrir, para ser dada por el autor a un lector que la recibe y así cambia su obrar". ${ }^{18}$ La obra se abre así al lector, es a él a quien está destinada, al contem plarla, seguirla, dejarse llevar por ella, en la dirección que ésta le propone, la recibe, la acoge y, según Ricoeur, cambia su obrar, es éste el momento de mímes is III.

En mímesis III habita el lector con la obra, ésta lo lleva desde su situación, al mundo que se abre por efecto de la lectura; ahí delante "lo que se comunica, en última instancia, es, más allá del sentido de la obra, el mundo que proyecta y que constituye su horizonte. En este sentido, el oyente o lector lo reciben según su propia capacidad de acogida, que se define también por una situación a la vez limitada y abierta sobre el horizonte del mundo". ${ }^{19}$ La lectura es la operación que nos permite salir de sí, para ir en busca de la obra que nos habla y con la que nos encontramos; así un nuevo mundo se despliega y se abre ante mi mirada y con ello nuevas posibilidades de sentir, de pensar y de actuar. Ricoeur manifiesta "el mundo es el conjunto de las referencias abiertas por todo tipo de textos descriptivos o poéticos que he leído, interpretado y que me han gustado. Comprender estos textos es interpolar entre los predicados de nuestra situación todas las significaciones que, de un simple entorno (Umwelt), hacen un mundo (Welt). En efecto, a las obras de ficción debemos en gran parte la ampliación de nuestro horizonte de existencia". 20

A nuestro ser el mundo pertenece el tiempo, como ya lo había establecido Heidegger; ${ }^{21}$ aunque Ricoeur mostrará además cómo se da "la refiguración efectiva del tiempo, convertido así en tiempo humano, por el entrecruzamiento de la his toria y de la ficción". 22 Hay un tiem po lineal, el del reloj, con el que nos miden y calculan, está ahí para manipular y organizar y hacernos disponibles para la eficiencia; otro el de la intratemporalidad "la intratemporalidad por ello, posee características propias que no pueden reducirse a la representación del tiempo lineal, como sucesión neutra de instantes abstractos. Estar en el tiempo es algo distinto a medir los intervalos que existen entre instantes-límites. Estar en el tiempo consiste principalmente en contar con él y, por tanto, en calcularlo. Pero

\footnotetext{
${ }^{16}$ RicoeurPaul. Tiempo y narración. Configuración del tiempo en el relato histórico, p. 151.

${ }^{17}$ Heidegger. Ser y Tiempo. México, Fondo de Cultura Económica, 1951, § 32, p. 172.

${ }^{18}$ RicoeurPaul. Tiempo y narración Configuración del tiempo en el relato histórico, p. 114.

${ }^{19}$ Idem p. 148.

${ }^{20}$ RicoerPaul. Tiempo y narración. Configuración del tiempo en el relato histórico, p. 152.

${ }^{21}$ Ricoeur toma de Heidegger su análisis de la temporalidad, pero para hacer un giro en la interpretación, que le permita constnir su tesis de tiempo y narración. ver Heidegger. Ser y tiempo, segundasección, p.p. 253-479.

${ }^{22}$ RicoeurPaul. Tiempo y narracción III. El tiempo narrado. México, Siglo Ventiuno Editores, 1996, p. 901. 
medimos el tiempo porque contamos con él y lo calculamos, no a la inversa". ${ }^{23}$ La narratividad permite, según Ricoeur, no sólo distinguir el tiempo lineal, de la intratemporalidad, sino que participa del movimiento que va de ésta a la historicidad; es así como "la narratividad y la temporalidad se encuentran estrechamente vinculadas, tan férreamente como pueden estarlo, según Wittgenstein, un juego de lenguaje y una forma de vida. Considero que la temporalidad es una estructura de existencia -una forma de vida- que accede al lenguaje mediante la narratividad, mientras que ésta es la estructura lingüística -el juego de lenguaje- que tiene como último referente dicha temporalidad. La relación, por tanto es recíproca. Un corolario importante de esta hipótesis de trabajo cons iste en que la diferencia evidente que existe entre la historia verdadera y el relato de ficción no es irreductible. La función narrativa, precisamente, alcanza su unidad fundamental debido a su capacidad de expresar, bien es cierto que de modo diferente, la misma tem poralidad profunda de la existencia". ${ }^{24}$

Una vez explicado el despliegue de este arco hermenéutico, Ricoeur se detiene en el esfuerzo que realizan las teorías de la narración y de la historia, por descronologizar la obra poética y desnarrativizar la historia, para ir mostrando cómo finalmente una y otra refieren nuestra condición histórica. Ni la ficción está cerrada sobre sí misma, ni se puede afimar que la narración no sea también una forma de explicar. "Nuestro problema, por tanto, consistirá en tratar de mostrar cómo a pesar de las diferencias que existen entre el alcance referencial de la ficción (pues también se refiere a algo) y el de la historia empírica, ambas contribuyen a describir o redescribir nuestra condición histórica”. ${ }^{25}$ El recorrido de Ricoeur es exhaustivo, una vez evidenciado lo anterior, la exigencia es presentar cómo la fenomenología del tiempo tampoco logra resolver la aporía del tiempo que expresó San Agustín: ¿¿Qué es entonces el tiempo? Si nadie me lo pregunta, lo sé y si trato de explicárselo a quien me lo pregunta, no lo sé" $(14,17){ }^{26}$ tal aporía no resuelta por el trabajo de la especulación, encuentra finalmente con Ricoeur una salida en la demanda de narración: "la temporalidad no se deja decir en el discurso directo de una fenomenología, sino que requiere la mediación de un discurso indirecto de narración". 27

Ricoeur es consciente de que el relato no es todo; "Viene así un momento, en una obra consagrada al poder que posee la narración de elevar el tiempo al lenguaje, en que es preciso confesar que el relato no es todo y que el tiempo se dice también de otro modo, porque para el propio relato, sigue siendo lo inescrutable". ${ }^{28}$ Ricoeur piensa, en este momento, en el poder de redescripción de la lírica; nosotros, por el contrario, dirigiremos nues tro atención a la retórica, para preguntar sobre el lugar que ésta ocupa en la constitución del mundo de la vida, y esbozar de manera tentativa su manera de referir el tiempo; no iremos has ta dónde ha

\footnotetext{
${ }^{23}$ RicoeurPaul. Historia y narratividad. Barcelona, Paidós, 1999, p. 187.

${ }^{24}$ Idem, p.p. $183-184$.

${ }^{25}$ Idem p. 84

${ }^{26}$ Citado por RicourPaul. Tiempo y narración I. Configuración del tiempo en el relato histórico, p. 45.

${ }^{27}$ RicoeurPaul. Tiempo y narración III. El tiempo narrado, p. 991.

${ }^{28}$ Idem p. 1.034. 
llegado Ricoeur con la historia y la literatura, pues esto seguramente excede nuestras posibilidades de reflexión hemenéutica, pero sí indicar y hacer algunas precisiones que pemitan seguir pensando sobre la retórica y sus vínculos con el mundo de la vida.

\section{El espacio público: la retórica}

Ricoeur en Retórica, Poética, Hermenéutica (1990), presenta la diferencia que se debe mantener entre las tres disciplinas: la retórica, la poética y la hemenéutica; "la retórica permanece como arte de argumentar con el fin de persuadir un auditorio de que una opinión es preferible a su rival. La poética permanece como arte de construir intrigas con el fin de ampliar el imaginario individual y colectivo. La hemenéutica permanece como el arte de interpretar los textos en un contexto distinto al del autor y de su auditorio inicial, con el fin de descubrir nuevas dimensiones de realidad. Argumentar, configurar, redescribir, tales son las operaciones mayores que la aspiración totalizante de cada una de ellas hace exclusivamente de una, la de las otras, pero que la finitud de su lugar original condena a la complementariedad". ${ }^{29}$ Una vez establecido de qué manera, según Ricoeur, la poética amplía el imaginario individual y colectivo, veamos que significa el poder que tiene la retórica para persuadir respecto a lo que es preferible.

La retórica apareció en el mundo griego. Conservamos de los antiguos hermosas piezas de discursos retóricos, testimonio del logro alcanzado por los griegos en el arte de componer discursos persuasivos, arte que, como tal, se enseñaba y era aprendido; era necesario para desempeñarse con maestría en los asuntos públicos. Descubierto este arte, los griegos adquieren conciencia del inmenso poder de la palabra, y surge así, también la tan temida Sofística, Ricoeur, en su libro de la Metáfora Viva, dice: "la técnica basada en el conocimiento de las causas que engendran la persuasión da un poder temible al que la domina perfectamente: el poder de disponer de las palabras sin las cosas y disponer de los hombres disponiendo de las palabras". "Así aparece la necesidad de su regulación y es Aristóteles, según Ricoeur, quien se ocupará de esta empresa "delimitar el empleo legítimo de la palabra poderosa, de trazar la línea que separa el uso del abuso, de establecer filosóficamente los vínculos entre la esfera de validez de la retórica y la esfera dominada por la filosofía. La retórica de Aristóteles constituye la más brillante de las tentativas de institucionalizar la retórica partiendo de la filosofía." ${ }^{31}$

Ricoeur, en La Metáfora Viva, considera que la retórica de Aristóteles abarca tres campos: "una teoría de la argumentación, que constituye su eje principal y que proporciona al mismo tiempo el nudo de su articulación con la lógica demostrativa y con la filosofía (esta teoría de la argumentación comprende por sí sola las dos

\footnotetext{
${ }^{29}$ RicoeurPaul."Rhétorique, poétque, herméneutique"(1990)En: Lectures 2. La contrée des philosophes, p.p.493494.

${ }^{30}$ RicoeurPaul. La metáfora viva, Madrid, Ediciones Cristiandad, 1980, p. 19.

${ }^{31}$ Idem p. 20. 
terceras partes del tratado), una teoría de la elocución y una teoría de la composición del discurso". ${ }^{2}$ Cada uno de estos campos construye nexos con saberes diferentes, la teoría de la argumentación con los Tratados de lógica, en especial con los Analíticos Primeros y los Analíticos Segundos, la teoría de la elocución con la Poética, y la teoría de la composición del discurso con los Tópicos y con Las Refutaciones Sofísticas.

Cuando Aristóteles enuncia la clase de pruebas que utiliza la retórica para persuadir, establece dos grupos diferentes; en el primero, dos formas: el entimema y el ejemplo "Y ciertamente en orden a demostrar, todos proporcionan pruebas por persuasión aduciendo ejemplos o entimemas". ${ }^{33}$ El segundo, tiene que ver con la consideración del discurso en situaciones es pecíficas de habla: "Entre las pruebas por persuasión, las que pueden obtenerse mediante el discurso son de tres especies: unas residen en el talante del que habla, otras en predis poner al oyente de alguna manera y las últimas, en el discurso mismo, merced a lo que éste demuestra o parecer demostrar". ${ }^{34}$ La anterior distinción responde a la idea que defienden por varios estudiosos, entre ellos Quintín Racionero; que estos dos tipos de pruebas proceden de épocas diferentes, pues en un comienzo se descartó la consideración de las pasiones y de los caracteres, para luego ser incluidos por Aristóteles, una vez realizado el estudio sobre los diferentes tipos de discursos retóricos: deliberativo, epidíctico y judicial. ${ }^{35}$ La presencia de estas últimas pruebas permite establecer una diferencia entre una retórica de carácter más general vinculada con la teoría de la argumentación y la teoría de la elocución y una retórica vinculada más a las situaciones específicas de habla.

\section{Retórica, teoría de la argumentación y teoría de la elocución}

La teoría de la argumentación se desarrolla, desde dos fomas de pruebas: entimemas y ejemplos; para Aristóteles, "el ejemplo es una inducción; por otra parte, el entimema es un silogismo". "Esto indica las fuertes conexiones que se establecen entre la Retórica y los Tratados de Lógica, en especial con los Analíticos Primeros; supone que una de las razones por las cuales se logra la persuasión se origina en el valor que concedemos a la lógica como garante de verdad. En los Analíticos Primeros, Aristóteles expone su teoría de los silogismos, allí encontramos una definición de la inducción o comprobación "la comprobación y el razonamiento de comprobación consiste en probar, a través de uno de los extremos, que el otro se da en el medio"; ${ }^{37}$ y el razonamiento probable que es "un razonamiento a partir de verosimilitudes o signos: aunque lo verosímil y el signo no son lo mismo, sino que lo verosímil es una proposición plausible: en efecto, lo que sabe que la mayoría de las veces ocurre así o no ocurre as í, o es o no es, eso

\footnotetext{
${ }^{32}$ Idem, p. 17.

${ }^{33}$ Aristóteles. Retórica, Traducción de Quintín Racionero, Madrid, Gredos, 1994, 1356b 5.

${ }^{34}$ Idem, 1356 a.

${ }^{35}$ Cfr. Introducción de Quintín Racionero. Retórica, p.p. 37-57.

${ }^{36}$ Aristóteles. Retórica, 1356 b.

${ }^{37}$ Aristóteles. “Analíticos Primeros”. En Tratados de lógica (Órganon) I. 68 b 15. 
es lo verosímil, v. g.: detestar a lo envidiosos, tener afecto a los amados. El signo, en cambio, quiere ser una proposición demostrativa, necesaria o plausible: en efecto si al existir algo, existe una cosa o, al producirse algo, antes o después se ha producido la cosa, aquello es signo de que se ha producido o de que existe dicha cosa." ${ }^{38}$ Este es el tipo de razonamiento que según la tradición recogida por Aristóteles, Cicerón y Quintiliano fue inventado por Córax, quien "ideó un método perfectamente organizado de debate cuando se hizo necesario establecer las actuaciones judiciales en los procesos relacionados con las propiedades que eran confis cadas por los tiranos".

Aristóteles distingue en el razonamiento probable, las verosimilitudes de los signos; esto permite, a su vez, establecer la conexión con los razonamientos dialécticos, los cuales encontramos caracterizados en los Tópicos: "es dialéctico el razonamiento construido a partir de cosas plausibles (...) son plausibles las que parecen bien a todos, o a la mayoría, o a los más conocidos y reputados". "Las verosimilitudes son entonces opiniones, que en el caso de la dialéctica son admitidas con el fin de examinar un deteminado problema y en la retórica, verdades, creencias, valores, que un grupo o una comunidad admiten, hacen suyos y mediante los cuales se dan a sí mismos una representación que los identifica; esto es lo que Ricoeur denomina, en sentido amplio, ideología, la cual asegura "la identidad de un grupo (nación, pueblo, partido etc.): en este sentido, la ideología es el discurso mismo de la constitución imaginaria de la sociedad. Pero es el mismo discurso que vira hacia la perversión, cuando pierde el contacto con el primer testimonio que habla sobre los acontecimientos de fundación y se hace discurso justificativo del orden establecido". " A partir de esta idea, podemos decir que por medio del discurso retórico el imaginario se hace presente, su poder persuasivo se explica por esta adhesión previa. ${ }^{42}$

El otro campo de la retórica, la elocución o lexis, establece nexos, no ya con la lógica sino con la poética. Ricoeur, citando a Aristóteles dice: "nadie duda que la conexión entre la teoría de la lexis y el resto del tratado, centrado en la argumentación, es muy débil. Pero no hay que confundir lo que quizás no sea más que un accidente de composición del tratado de Aristóteles con la ausencia de conexión lógica entre pisteis y lexis; 'no basta con tener argumentos que presentar, es necesario también proponerlos de manera convincente, y esto contribuye a que el discurso aparezca con un carácter determinado'". 43 La elocución hace aparecer el discurso mediante las figuras o tropos, es así, pues debe ser visible para el auditorio a quien se dirige, hacer ver, es otro elemento de la persuasión. No persuadimos solamente cuando hablamos a la razón y des de lo

\footnotetext{
${ }^{38}$ Idem, 70 a10.

${ }^{39}$ Murphy, Mames J. Sinopsis histórica de la retórica clásica. Madrid, Gredos, 1989, p. 14.

${ }^{40}$ Aristóteles. “Tópicos” En: Tratados de lógica (Órganon) I. 100² 25-100b 20.

${ }^{41}$ RicoeurPaul. "Rhétorique, poétique, herméneutique" (1990) En: Lectures 2. La contrée des philosophes. p. 482.

${ }^{42}$ Desde este campo de la retórica se han construido teorías de la argumentación como las de Stephen Toulmin, la cual es retomada por Jurgen Habermas en su teoría de la acción comunicativa, y la de Chaïm Perelman y Lucie Olbrechts-Tyteca, de la cual a su vez Habermas extrae la idea del auditorio universal.

${ }^{43}$ RicoeurPaul. La metáfora viva. p. 51. 
que admitimos como verdad, sino también desde lo que podemos percibir como tal, la verdad sobre las acciones no son sólo racionales sino también empíricas.

La conexión entre la retórica y la poética, la muestra Paul Ricoeur, a partir del doble tratamiento que hace Aristóteles de la lexis en cada uno de los tratados, Poética y Retórica. La primera definición de la metáfora que conocemos en la historia del pensamiento, es la de la Poética: "es la traslación de un nombre ajeno, o desde el género a la especie, o desde la especie al género, o desde una especie a otra especie, o según la analogía". "Esta definición agruparía todo el campo de las figuras que conocemos hoy, las cuales eran especies de metáfora. En la Retórica aparece también la metáfora, pero allí Aristóteles remite a la definición dada en la Poética; ello señala el lugar de origen. A Ricoeur le gusta decir que la obra es una metáfora en miniatura, podríamos decir que la obra despliega una metáfora, pemite la ampliación del imaginario. En la retórica, la metáfora está al servicio de la persuasión, ya ha sido creada, solamente las volvemos a traer. Ponemos delante de nosotros, lo que se encuentra a nuestras espaldas, lo usamos para persuadir, en esto radica su poder y su perversión. Pero, también la poética puede, por su poder de construir utopías, servir para desencadenar las mayores atrocidades. ${ }^{45}$

\section{La retórica en situación}

Para Ricoeur, la retórica "no puede convertirse en una disciplina puramente argumentativa, porque se dirige al oyente; por eso, no puede olvidar el carácter del orador y la disposición del auditorio; en una palabra se sitúa en la dimensión intersubjetiva y dialogal del uso público del discurso. De ello se deduce que la consideración de las emociones, de las pasiones, de las costumbres, de las creencias compete a la retórica aun cuando no debe suplantar la prioridad del argumento veros ímil; el argumento propiamente retórico tiene en cuenta a la vez el grado de verosimilitud de lo que se discute y el valor persuasivo que afecta al locutor y al oyente". 46

Las teorías de la argumentación de Perelman y Lucie Olberchtzs-Tyteca y de Stephen Toulmin, desconocen el lugar del deseo y de la sensibilidad como componentes de la persuasión. Para Ricoeur, el deseo debe ser incluido como uno de sus componente esenciales "la idea de que la razón sea por sí misma práctica, es decir que ordene en tanto razón sin consideración del deseo, me parece aun más lamentable. Compromete a la moral en una serie de dicotomías mortales para la noción misma de acción, algo que la crítica hegeliana denuncia con toda razón. Forma contra contenido, ley práctica contra máxima, deber contra

\footnotetext{
${ }^{44}$ Aristóteles. La Poética. Traducción de Valentín García Yebra, Madrid, Gredos, 1992, 1457 b 5-10.

${ }^{45}$ ChaïmPerelman y Lucie Olbrechts- Tyteca, integran, también a su tratado de la argumentación, la elocución, haciendo de ella, esquemas argumentativos (enlaces que fundamentan la estructura de lo real) y con ello reconocen el poder persuasivo que tienen las figuras retónicas. Ver Perelman Chïm, Olbrechts- Tyteca Lucie. Tratado de la Argumentación. La nueva retórica, Madrid, Gredos, 1989, p.p. 536-626.

${ }^{46}$ Ricoeur. La metáfora viva. p. 49. 
deseo, imperativo contra felicidad. Aquí también Aristóteles explica mejor la estructura específica del orden práctico, cuando forja la noción de deseo deliberativo y unía deseo recto y pensamiento justo en su concepto de phrónesis". 47

El reconocimiento de Aristóteles de esta doble dimensión que actúa en la acción, no le permitió seguramente pensar una retórica que, por tener su lugar en el mundo de la vida, desconociera el deseo, las pasiones y las virtudes como parte fundamental de la persuasión. Podemos entonces, explicar por qué considera otro tipo de pruebas además del entimema y el ejemplo, las que tienen que ver con el talante del orador, con la predisposición del oyente y por supuesto con el discurso mismo; en este sentido podemos hablar de un cuarto campo, que aunque Ricoeur no lo desconoce, pues lo incluye en el campo de la lexis, merecería un estudio aparte, las pasiones.

La tesis de Quintín Racionero consiste en que la consideración de este otro tipo de pruebas procede de su estudio de los géneros de discursos, lo cual no podría ser de otro modo; pues es allí, en cada uno de los espacios en los que actúa, donde se juega propiamente la persuasión, así lo reconoce Ricoeur: "La retórica se aplica a situaciones concretas: la deliberación de una asamblea política, el juicio de un tribunal, el ejercicio público de la alabanza y de la crítica; estos tres tipos de situación de discurso definen los tres géneros de la retórica: deliberativo, judicial y epidíctico" ${ }^{48}$

Gran parte del libro I de la Retórica, está dedicado a ellos "tres son en número las especies de retórica, dado que otras son las clases de oyentes de discursos que existen. Porque el discurso consta de tres componentes: el que habla, aquello de lo que habla yaquél a quien habla; pero el fin se refiere a este último; quiero decir al oyente. Ahora bien, el oyente es por fuerza, o un es pectador o uno que juzga; y en este último caso, o uno que juzga sobre cosas pasadas o sobre cosas futuras. Hay, en efecto, quien juzga sobre el futuro, como por ejemplo un miembro de una asamblea, y quien juzga sobre suces os pasados, como hace el juez; el espectador por su parte, juzga sobre la capacidad del orador". ${ }^{49}$ Cada uno de estos discursos tienen su lugar de realización en espacios específicos, orientados por ello a fines diversos: la asamblea donde se delibera sobre lo conveniente, los estrados judiciales donde se debe llegar a un veredicto final sobre lo justo o injusto; los juegos olímpicos, donde se presenta lo digno de ser alabado o censurado. Al estar situado, a su vez establece relaciones divers as con el tiempo: se delibera sobre lo futuro, se establece un veredicto sobre acciones que ocurrieron en el pasado, y en el presente acciones dignas de ser alabadas o censuradas. La prioridad que se le da en cada uno de los discursos a uno de los tiempos, no significa que se desconozca la presencia de los otros, pues, al deliberar sobre el futuro lo hacemos trayendo la experiencia del pasado, o proyectando lo no realizado en el futuro o

\footnotetext{
${ }^{47}$ RicoeurPaul."La razón práctica”. En: Del texto a la acción. Ensayos de Hermenéutica II. p. 230.

${ }^{48}$ Ricoeur. La metáfora viva. p. 48.

${ }^{49}$ Aristóteles. Retórica. 1358 a $351358 b 5$. 
anticipando posibilidades futuras; al juzgar traemos al presente los hechos pasados para emitir un juicio sobre ellos, con esto, a su vez, creamos un precedente para futuras decisiones, y finalmente con respecto a lo que es digno de ser elogiado o censurado, traemos acciones del pasado hacia el presente y con ello creamos modelos o antimodelos de acciones para el presente y el futuro.

La retórica forma el juicio: "la retórica tiene por objeto formar un juicio (dado que también se juzgan las deliberaciones y la propia acción judicial es un acto de juicio)". ${ }^{50}$ Es propiamente en el juicio que se enuncia lo preferible, porque no basta saber sobre la justicia o la bondad, sino establecer en cada caso que es lo bueno o lo justo. Esto sólo se logra si se aprecian todos los componentes de la acción (red conceptual, estructuras simbólicas) y, en el caso de la retórica, el lugar y el tiempo específico, con el fin de construir los argumentos apropiados a la situación que se considera, según lo pertinente y oportuno, y así tomar las decisiones y proponer las valoraciones. La prudencia nos da este tipo de sabiduría. Pero no sólo por decidir con prudencia, persuadimos a los oyentes; jueces, miembros de la asamblea, o espectadores, sino que el orador debe aparecer cómo un hombre virtuoso, por lo tanto digno de ser escuchado y en el caso de los oyentes; a estos se les debe propiciar estados afectivos que los dispongan a escuchar y a emitir sus juicios, "las cosas no son, desde luego, iguales para el que siente amistad, que para el que experimenta odio, ni para el que está airado que para el que tiene calma, sino que son por completo dis tintas o difieren en magnitud". 51

En el libro II de la Retórica, encontramos una caracterización de cada una de las pasiones: "Porque las pasiones son, ciertamente, las causantes de que los hombres se hagan volubles y cambien en lo relativo a sus juicios, en cuanto que de ellas se siguen pesar y placer. Así son, por ejemplo, la ira, la compasión, el temor y otras más de naturaleza semejante y sus contrarios. Ahora bien en cada una se deben distinguir tres aspectos: en relación a la ira -pongo por caso-, en qué estado se encuentran los iracundos, contra quiénes suelen irritarse y por qué asuntos; pues si sólo contamos con uno de es tos aspectos, pero no con todos, no es posible que se inspire la ira. Y lo mismo ocurre con las demás pasiones. En consecuencia, pues, de igual modo que en nuestros anteriores anális is hemos descrito los corres pondientes enunciados, as í procederemos también con respecto a las pasiones y las dividiremos de acuerdo con el método establecido". 52 Las pasiones tienen que ver con la relación que establecemos con el mundo y con los otros, ellas se configuran por esta experiencia, hacen parte de nuestro mundo de la vida y pueden ser dichas. A partir de este decir, Aristóteles cons truye una serie de tipologías, desde sus características esenciales, que ciertamente son culturales, como bien lo establece David Le Breton en su libro Las pasiones ordinarias. Antropología de las emociones: "De una sociedad humana a otra, los hombres experimentan afectivamente los acontecimientos de su existencia a través de repertorios culturales diferenciados que a veces se parecen, pero no son

\footnotetext{
${ }^{50}$ Idem 1377 b 20.

${ }^{51}$ Idem 1377 b 301378 a.

${ }^{52}$ Idem, 1378 a 20-25. 
idénticos" "53; asegura, estas "emociones nacen de una evaluación más o menos lúcida de un acontecimiento por parte de un actor nutrido con una sensibilidad propia; son pensamientos en acto, apoyados en un sistema de sentidos y valores". "Si nuestras emociones y pasiones, son un producto cultural, la tipología que encontramos en Aristóteles, permite construir enunciados persuasivos para su comunidad; en nuestro caso ¿haría falta, entonces, la construcción de una tipología que diera cuenta de nuestras emociones?. Olbeth Hansberg, en su libro La diversidad de las emociones, especifica que en la historia del pensamiento se han utilizado términos diversos para hablar de los mismos estados mentales: pasión, emoción y afecto. Aris tóteles pensaba que el "origen de las emociones era el reconocimiento de algo como bueno o malo como adecuado o inadecuado. La experiencia sensorial conduce a la emoción porque el individuo interpreta algo experimentado como bueno o malo para él". "Si ésta es la conexión que realiza Aristóteles de la emoción con lo bueno o lo malo, es posible entender la importancia de elaborar una retórica de las pasiones, pues si ella está orientada a persuadir sobre lo preferible, es posible conducir a una deteminada pasión, cuando se experimenta e interpreta, lo que se presenta y dice mediante un discurso. Pero aquí radica, aún más, el peligro de la retórica: ella conduciría ciertamente a la manipulación de nuestras emociones.

Hasta aquí hemos presentado los distintos componentes de la persuasión: razón, elocución, pasión. Todos ellos deben estar presentes; sólo con ellos es posible disponer o mover a la acción, ellos involucran a todo el ser humano, su razón, su sensibilidad, sus emociones. Ricoeur al afirmar que la retórica, en Aristóteles, es tá orientada a persuadir sobre lo preferible, asegura los vínculos que ésta debe tener con la ética y la política; al mantener los lazos con la lógica, garantiza, en alguna medida, su aspiración a la verdad y, finalmente, al establecer relaciones con la poética y con las pasiones, ocupa su lugar en el mundo de la vida; con ello, se puede decir responde a los desafíos de la Sofística y ya no puede ser utilizada con no importa que propósitos. Una retórica que, esencialmente, se orienta a la formación del juicio, no debe olvidar lo anterior, so pena de caer en la manipulación. Tanto la poética como la retórica, tienen su lugar de origen y despliegue en el mundo de la vida; reconocerlo, pemite un mayor conocimiento sobre el imaginario que nos constituye, que mueve nues tras acciones, y el que se amplía. La elucidación de la ontología que se constituye en este desplegarse del discurso poético y retórico permite ampliar nuestra comprensión de las acciones humanas, con lo que, se mantiene el diálogo con las Ciencias Sociales.

\footnotetext{
${ }^{53}$ Le Breton David. Las pasiones ordinarias. Antropología de las emociones. Buenos Aires, Nueva Visión, 1998 , p..9.

${ }^{54}$ Idem, p. 11.

${ }^{55}$ Hansberg Olbeth. La diversidad de las emociones. México, Fondo de Gultura Económica, 1996, p. 20. 


\section{BIBLIOGRAFÍA CITADA}

ARISTÓTELES. La Poética. Traducción de Valentín García Yebra. Madrid, Gredos, 1992; pp. 542.

ARJSTOTELES. Retórica. Traducción de Quintín Racionero, Madrid, Gredos, 1994; pp. 626.

ARISTOTELES. Tratados de lógica (Organon) 1. Madrid, Gredos, 1982; pp. 390.

HANSBERG, Olbeth. La diversidad de las emociones. México, Fondo de cultura Económica, 1996; pp. 199.

HEIDEGGER, Martin. Sery Tiempo. México, Fon do de Cultura Económica, 1951.

HOYOS VÁSQUEZ, Guillermo \& VARGAS GUILLÉN, Germán. La teoría de la acción comunicativa como nuevo paradigma de investigación en ciencias sociales: las ciencias de la discusión. Bogotá, ICFES, ASCUN, 1996; pp. 285.

LE BRETON, David. Las pasiones ordinarias. Antropología de las emociones. Buenos Aires, Nueva Visión, 1998; pp. 254.

MURPHY, Mames H. Sinopsis histórica de la retórica clásica. Madrid, Gredos, 1989; pp. 283.

PERELMAN, ChaYm \& OLBRECHTS-TYTECA, Lucie. Tratado de la Argumentación. La nueva retórica. Madrid, Gredos, 1989; pp. 855.

RICOEUR, Paul. "Rhétorique, poétique, herméneutique" (1990). En: Lectures 2. La contrée des philosophes. Paris Seuil, 1992; pp. 479-494.

RICOEUR, Paul. Del texto a la acción. Ensayos de hermenéutica II. México, Fondo de Cultura Económica, 2002; pp. 380.

RICOEUR, Paul. Hermenéutique. Louvain-laNueve. Cours Cours professé a L'institut supérieur de Philosophie 1971-1972; Editions du SIC. pp. 228.

RICOEUR, Paul. His toria y narratividad Barcelona, Paidós, 1999; pp. 230.

RICOEUR, Paul. La metáfora viva. Madrid, Cristiandad, 1980; pp. 437.

RICOEUR, Paul. Tiempo y narración 1. Configuración del tiempo en el relato histórico. México, Siglo XXI, 1995; pp. 371.

RICOEUR, Paul. Tiempo y narración III. El tiempo narrado. México, Siglo XXI, 1996; pp. 1074. 